\section{River Listening: ACOUSTIC ECOLOGY AND AQUATIC BIOACOUSTICS IN GLOBAL RIVER SYSTEMS}

Leah Barclay, Griffith University, Brisbane, Australia. Email: <1.barclay@griffith.edu.au>.

Toby Gifford, Griffith University, Brisbane, Australia. Email: <t.gifford@griffith.edu.au>.

Simon Linke, Griffith University, Brisbane, Australia. Email <s.linke@griffith.edu.au>.

See $<$ mitpressjournals.org/toc/leon/51/3 $>$ for supplemental files associated with this issue.

\section{Submitted: 21 October 2016}

\section{Abstract}

River Listening is an interdisciplinary research project exploring the cultural and biological diversity of global river systems through sound. The project examines the creative possibilities of accessible and noninvasive recording technologies to monitor river health and engage local communities in the conservation of global river systems. River Listening combines emerging fields of science with acoustic ecology, creativity and digital technology to further the understanding of aquatic biodiversity and inspire action at a time when the conservation and management of freshwater ecosystems is a critical priority.

River Listening was developed through a Synapse Residency awarded to Dr Leah Barclay and The Australian Rivers Institute in 2014. The Synapse program is a joint initiative of the Australia Council for the Arts and the Australian Network for Art and Technology, which supports research collaborations between leading artists and scientists in Australia. The first phase of River Listening was designed to explore the artistic and scientific possibilities of hydrophone (underwater) recording and inspire community engagement through interactive workshops, recording expeditions and installations designed to draw attention to the sounds beneath the surface of the river.

The creative foundations for River Listening emerged out of a body of Leah Barclay's artistic practice spanning 10 years of collaboration with river communities across the world. These creative projects involve live performances, immersive installations and interdisciplinary collaborations designed to bring attention and awareness to rivers as the lifeblood of communities [1]. Sound Mirrors (2009-2011) and The DAM(N) Project (2011-2013) were among the largest of these initiatives, involving collaborations with remote communities across India, Brazil, China and Australia. During these projects, the value of hydrophone recordings as a monitoring tool for river health became apparent. Looking at the surface of a river, it is virtually impossible to detect the health of the ecosystem. The hydrophones provided access to another way of understanding the river and often exposed a dynamic and engaging soundscape just beneath the surface. The impacts of climate change are often visible in terrestrial environments, yet dramatic changes in river systems can go unnoticed simply due to visibility.

Considering the current biodiversity crisis and the dramatic impact on freshwater ecosystems, it would seem logical for aquatic bioacoustics to be an active monitoring tool in river systems. Recent years have seen a dramatic increase in bioacoustics and ecoacoustics for non-invasive environmental monitoring, yet the large majority of this work has focused on terrestrial and marine environments, with very few studies exploring freshwater environments. Initial studies in the 1960s focused on identifying and cataloging soniferous fish sounds [2] while more recent research in France has taken an ecoacoutics approach by studying acoustic communities in freshwater environments [3]. Research led by Diego Tonolla adopts an acoustic ecology approach by exploring acoustic patterns from a holistic perspective that incorporates the physical habitat of the river ecosystem [4].

The scientific grounding for River Listening is led by freshwater ecologist Dr Simon Linke. Dr Linke's pioneering work in biomonitoring and river conservation planning has been used by agencies and NGOs from South East Queensland to the Congo and he has recently been investigating aquatic bioacoustics and real-time ecosystem monitoring in freshwater environments using passive acoustics. Dr Linke believes that classic techniques for measuring aquatic biodiversity are problematic as they potentially injure the study organism (such as electrofishing) and can be bias as they only provide a brief snapshot at the time of observation. He believes that passive acoustics presents a noninvasive and unexplored approach to freshwater ecosystem monitoring. This theory is shared by $\mathrm{Dr}$ Toby Gifford, the third collaborator on River Listening who is a music technologist and software programmer active in a wide spectrum of interdisciplinary collaborations.

River Listening was initially developed across four Queensland river systems: the Brisbane River, the Mary River, the Noosa River and the Logan River. The initial phase of the project involved listening labs, field recording, sound mapping, performances and installations to experiment with hydrophonic recording, virtual technologies and community engagement in understanding river health and aquatic biodiversity. The process involved not just recording and listening, but collaborating with communities, exploring scientific measurement tools, comparing aquatic soundscapes, and responding and adapting to other processes that emerged. River Listening has expanded into various other communities across Australia, Europe and North America and has established an interdisciplinary framework that is adaptable and responsive to each community and river system. This process involves workshops, hydrophone recording, sound mapping and collaborative installations. Education and community engagement remains to be a core focus of River Listening and many of the leading scholars in freshwater bioacoustics have been actively advocating for education. This includes Dr. Rodney Rountree, a marine biologist and fish ecologist who predicted "with the advent of new acoustic technologies, passive acoustics will become one of the most important and exciting areas of fisheries research in the next decade" [5]. While he has produced some of the most important scientific studies on soniferous fish, he has placed equal importance on public outreach and education, including producing a children's e-book titled Listening to Fish: New Discoveries in Science available from his website [6].

It should be noted that the practice of recording underwater sounds of rivers with hydrophones is not considered new or emerging in artistic disciplines; it has been pursued by artists for decades. Annea Lockwood has been actively recording rivers since the 1960s, beginning with her river archive of field recordings which evolved into her iconic river sound maps; $A$ Sound Map of the Hudson River (1982), A Sound Map of the Danube (2005) and A Sound Map of the Housatonic River (2010) [7]. The soundscapes of rivers feature prominently in the work of Ros Bandt, particularly in compositions including Voicing the Murray (1996) and Blue Gold (2005) [8]. Julie Freeman's work The Lake (2005) used an array of hydrophones to track fish in real-time for a period of six weeks. Freeman used a sophisticated electronic tagging system to transform the natural biological movement of the fish into sound for a sitespecific installation [9]. David Monacchi's multi-channel composition Stati d'Acqua (2006) brought attention to the Tiber 
River in Rome through processed field recordings exploring the physical transformations of water [10]. Jana Winderen is an artist with a background in mathematics, chemistry and fish ecology that has explored the sounds of underwater insects as a measure for freshwater health. Winderen's most recent installation Vandrere (2016) examines the fish migrations in the Aker River and inner Oslo Fjord through underwater recordings that are juxtaposed with sounds from other aquatic environments where fish and mammals migrate [11]. These examples are just a selection of artists pioneering the use of hydrophone recordings to inspire scientists and bring awareness to freshwater ecosystems.

The creative outcomes from River Listening, including installations and performances drawing on our evolving database of hydrophone recordings, are central to our public engagement and awareness efforts. The interdisciplinary balance of River Listening is evident in our augmented reality sound walks, which can be experienced by walking along global river systems with a mobile device and triggering geo-located soundscapes that explore the cultural and biological diversity of the river. These augmented reality sound walks are designed to transform a personal mobile phone into a sonic compass by guiding listeners along the riverbank to explore geo-located soundscapes and live hydrophones. These creative outcome draw on Barclay and Gifford's ongoing research into mobile technologies, sonic art and locative media as tools for ecological engagement.

The first River Listening augmented reality sound walk launched on the Noosa River in Australia in August 2015 [12] and has since featured on river systems across Australia, Europe and the USA including the Hudson River for Climate Week NYC in 2015 and the Seine River for COP 21 in Paris [13]. The diverse soundscapes are geo-located in direct relation to a relevant part of the riverbank. Along Noosa River, snapping shrimp become louder towards the jetty, community voices arise at landmarks and the sounds of deep hydrophones draw listeners closer to the waters edge. These augmented reality sound walks inspire communities to explore the river in new ways and hear sounds beneath the surface they would not usually think about. The installations are created in collaboration with communities and often hosted as part of festivals and events where extended engagement can occur. While many consider mobile technologies key factors in ecological disconnection, particularly amongst the younger generations, this project explores the possibilities for repurposing these technologies to reconnect us to the environment and reveal ecological systems through accessible creative technology.

The River Listening team have been developing a customised digital platform, sound maps and mobile application that will allow communities to upload and compare recordings to explore the cultural and biological diversity of global river systems through sound. The project continues to expand at micro and macro levels, ranging from education programs with community groups in remote Australia to partnerships with UNESCO to implement acoustic monitoring in biosphere reserves across South America and the Asia-Pacific region [14].

As rivers across the world continue to be impacted by human activity and rapid ecological changes, River Listening is designed to bring attention to rivers through acoustic ecology, creative technology and community engagement while being deeply grounded in the scientific possibilities of hydrophone recording. The international interest in the possibilities of aquatic bioacoustics and ecoacoustics continues to expand and there are clear opportunities to harness virtual technologies to develop accessible community engagement around the creative and scientific possibilities of listening to the environment. The necessary recording technologies have become increasingly accessible and affordable, so empowering local communities to undertake the mapping of environmental change in collaboration with artists and scientists is now realistic and possible.

River Listening is a catalyst for interdisciplinary thinking at a time when the management of aquatic ecosystems is a critical priority. We urgently need to engage communities in river conservation and find new techniques that can provide reliable ecological information to decision makers. River Listening extends and expands acoustic ecology as an inclusive, socially engaged, accessible, interdisciplinary field that can inspire communities across the world to listen to the environment and explore the cultural and biological diversity of global rivers through sound.

\section{References and Notes}

1. Leah Barclay, "River Listening," in Frederick Bianchi and V. J. Manzo, eds., Environmental Sound Artists: In Their Own Words (New York, USA: Oxford University Press, 2016).

2. Marie Poland Fish and William H. Mowbray. Sounds of Western North Atlantic Fishes. A Reference File of Biological Underwater Sounds (London, UK: Johns Hopkins Press, 1970).

3. Camille Desjonquères, Fanny Rybak, Marion Depraetere, Amandine Gasc, Isabelle Le Viol, Sandrine Pavoine and Jérôme Sueur, "First Description of Underwater Acoustic Diversity in Three Temperate Ponds," PeerJ 3 (2015) $<$ https://peerj.com/articles/1393/>

4. Diego Tonolla, Mark S. Lorang, Kurt Heutschi, Chris C. Gotschalk and Klement Tockner, "Characterization of Spatial Heterogeneity in Underwater Soundscapes at the River Segment Scale," Limnology and Oceanography 56, No. 6 (2011). pp. 2319-2333.

5. Rodney A. Rountree, R. Grant Gilmore, Clifford A. Goudey, Anthony D. Hawkins, Joseph J. Luczkovich and David A. Mann, "Listening to Fish: Applications of Passive Acoustics to Fisheries Science," Fisheries 31, No. 9 (2006) pp. 433-446.

6. Rodney A. Rountree, "Listening to Fish: New Discoveries in Science," $<$ www.fishecology.org/soniferous/soniferous.htm> (accessed 3 September 2015).

7. Annea Lookwood, "Compositions,"

<www.annealockwood.com/compositions.htm> (accessed 14 March 2015).

8. Ros Bandt <www.rosbandt.com> (accessed 11 August 2016).

9. Julie Freeman, "The Lake" (2005), <www.translatingnature.org/lake/> (accessed 14 March 2015).

10. David Monacchi, "Stati d'Acqua" (2006),

<www.davidmonacchi.it/media/audio/water.htm> (accessed 14 March 2015).

11. Jana Winderen, "Vandrere" (2016), <www.tenthaus.no/exhibitions/51-janawinderen-vandrere $>$ (accessed 20 October 2016).

12. Leah Barclay, "WIRA: River Listening" (2016),

$<$ www.leahbarclay.com/wira> (accessed 20 October 2016).

13. River Listening, ArtCOP 21 (2015), <www.artcop21.com/events/riverlistening/> (accessed 20 October 2016).

14. Biosphere Soundscapes, (2016), <www.biospheresoundscapes.org/> (accessed 20 October 2016). 